\title{
Incidence, risk factors, and prognostic indicators of symptomatic air embolism after percutaneous transthoracic lung biopsy: a systematic review and pooled analysis
}

\author{
Jong Hyuk Lee ${ }^{1}$ Soon Ho Yoon ${ }^{1}$ (D) Hyunsook Hong ${ }^{2} \cdot$ Ji Young Rho $^{3} \cdot$ Jin Mo Goo $^{1}$ \\ Received: 30 June 2020 /Revised: 31 August 2020 / Accepted: 5 October 2020 / Published online: 13 October 2020 \\ (C) The Author(s) 2020
}

\begin{abstract}
Objectives To determine the incidence, risk factors, and prognostic indicators of symptomatic air embolism after percutaneous transthoracic lung biopsy (PTLB) by conducting a systematic review and pooled analysis.

Methods We searched the EMBASE and OVID-MEDLINE databases to identify studies that dealt with air embolism after PTLB and had extractable outcomes. The incidence of air embolism was pooled using a random effects model, and the causes of heterogeneity were investigated. To analyze risk factors for symptomatic embolism and unfavorable outcomes, multivariate logistic regression analysis was performed.

Results The pooled incidence of symptomatic air embolism after PTLB was $0.08 \%$ (95\% confidence interval [CI], $\left.0.048-0.128 \% ; I^{2}=45 \%\right)$. In the subgroup analysis and meta-regression, guidance modality and study size were found to explain the heterogeneity. Of the patients with symptomatic air embolism, 32.7\% had unfavorable outcomes. The presence of an underlying disease (odds ratio [OR], 5.939; 95\% CI, 1.029-34.279; $p=0.046$ ), the use of a $\geq 19$-gauge needle (OR, 10.046; 95\% CI, 1.103-91.469; $p=0.041)$, and coronary or intracranial air embolism $(\mathrm{OR}, 19.871 ; 95 \% \mathrm{CI}$, $2.725-14.925 ; p=0.003)$ were independent risk factors for symptomatic embolism. Unfavorable outcomes were independently associated with the use of aspiration biopsy rather than core biopsy (OR, 3.302; 95\% CI, 1.149-9.492; $p=$ $0.027)$ and location of the air embolism in the coronary arteries or intracranial spaces $(\mathrm{OR}=5.173 ; 95 \% \mathrm{CI}=1.309$ 20.447; $p=0.019)$.

Conclusion The pooled incidence of symptomatic air embolism after PTLB was $0.08 \%$, and one-third of cases had sequelae or died. Identifying whether coronary or intracranial emboli exist is crucial in suspected cases of air embolism after PTLB.

Key Points

- The pooled incidence of symptomatic air embolism after percutaneous transthoracic lung biopsy was 0.08\%, and one-third of patients with symptomatic air embolism had sequelae or died.

- The risk factors for symptomatic air embolism were the presence of an underlying disease, the use of a $\geq 19$-gange needle, and coronary or intracranial air embolism.

- Sequelae and death in patients with symptomatic air embolism were associated with the use of aspiration biopsy and coronary or intracranial locations of the air embolism.
\end{abstract}

Keywords Radiology, interventional $\cdot$ Embolism, air · Biopsy $\cdot$ Lung

Soon Ho Yoon

yshoka@gmail.com

1 Department of Radiology, Seoul National University Hospital, Seoul National College of Medicine, Seoul, South Korea
2 Medical Research Collaborating Center, Seoul National University Hospital, Seoul, South Korea

3 Wonkwang University Hospital, Wonkwang University College of Medicine, Iksan, South Korea 


\section{Abbreviations}

COPD Chronic obstructive pulmonary disease

PTLB Percutaneous transthoracic lung biopsy

\section{Introduction}

Percutaneous transthoracic lung biopsy (PTLB) is a wellestablished image-guided procedure for the diagnosis of lung parenchymal lesions $[1,2]$ with excellent diagnostic accuracy $[3,4]$. Nevertheless, PTLB can be accompanied by complications, including pneumothorax ( 9 to $54 \%$ with an average of around $20 \%$ ), lung parenchymal hemorrhage (11\%), and hemoptysis (5.2 to 7\%) [5-7]. The majority of these complications can be managed conservatively or with a minimal intervention, such as percutaneous tube drainage, without any sequelae $[5,6,8]$.

Air embolism is another complication of PTLB [6-11]. It occurs extremely rarely [12-14], but can result in mortality or sequelae [15-17], and therefore constitutes a significant concern for radiologists. However, recent studies have reported cases with symptomatic air embolism after PTLB that resolved without sequelae $[6,8,18,19]$. Due to the rarity of air embolism, most of the relevant publications reported a single case or a few cases, hampering a comprehensive understanding of air embolism after PTLB. A systematic review, followed by a pooled analysis, is a way to synthesize information from all the relevant publications regarding air embolism after PTLB. Thus, we conducted a systematic review and pooled analysis to determine the incidence, risk factors, and prognostic indicators of symptomatic air embolism after PTLB.

\section{Materials and methods}

This systematic review was performed and reported in compliance with the Preferred Reporting Items for Systematic Reviews and Meta-Analyses (PRISMA) guidelines. The protocol of this study was registered in the International Prospective Register of Systematic Reviews (ID: CRD42019141479).

\section{Search strategy}

We searched the EMBASE and OVID-MEDLINE databases to identify relevant publications with the following search terms: [(lung OR pulmonary) AND \{ (percutaneous OR transthora*) OR (biops* OR aspira* OR needle)\}] AND $\{($ air AND embol*) OR (gas AND embol*)\}. The initial search was undertaken on May 8, 2019, and updated on January 5, 2020. We only included articles published in English without any limits on publication year.

\section{Eligible criteria for study selection}

We reviewed all the searched publications regardless of the study type. The inclusion criteria were as follows: (a) studies with one or more patients suspected of having air embolism after PTLB, (b) confirmation of the presence of air embolism by autopsy or computed tomography (CT), and (c) sufficient data described in detail to extract the final outcomes and the variables associated with air embolism. We applied the following exclusion criteria: (a) studies with individuals who underwent bronchoscopic lung biopsy, not PTLB, and (b) individuals who underwent percutaneous needle localization, rather than biopsy.

We only included case reports, case series, prospective or retrospective cohort studies, and case-control studies, not letters, editorial comments, abstracts, review articles, guidelines, or consensus statements. Full-text articles were assessed for eligibility independently by two authors (J.H.L. and S.H.Y. with 7 and 14 years of experience in thoracic radiology, respectively). Any discrepancy was resolved by consensus.

\section{Data extraction}

For data extraction, the two authors (J.H.L. and S.H.Y.) independently reviewed all eligible articles and extracted the following data using a standardized spreadsheet in Microsoft Excel 2016 (Microsoft Corporation): study characteristics, population characteristics, radiological characteristics of the biopsied lesion, information related to PTLB, information related to air embolism, and prognosis. In addition to this review, we tried to contact the corresponding authors of each study via e-mail for missing or unreported data.

\section{Methodological quality assessment of individual studies}

Quality assessment was performed according to the tool proposed by Murad et al, which is composed of eight items categorized into four domains [20]. Three items in the causality domain were not adopted because they are mostly relevant to cases of adverse drug events [20]. We assessed the methodological quality of individual studies based on the five remaining items according to each purpose, which dealt with selection, ascertainment of exposure, causality, and reporting [20].

\section{Data synthesis and statistical analysis}

We estimated the pooled incidence using a random-intercept logistic regression model, which is preferred over conventional approximate methods, especially for rare events [21]. Heterogeneity across the included studies was evaluated using the $I^{2}$ statistic, which was derived from the Cochran $Q$ statistic using the following equation, $I^{2}=100 \% \cdot(Q-\mathrm{df}) / Q$. An $I^{2}$ 
statistic $>50 \%$ was regarded as indicating substantial heterogeneity. A subgroup analysis and meta-regression were performed to investigate the causes of heterogeneity with the following covariates: guidance modality (CT guidance versus other modalities), study size ( $\geq 2500$ vs. $<2500$ ), and publication year (before 2000 vs. after 2000). The potential for publication bias was evaluated through a visual assessment of funnel plots of sample size against incidence due to the sparse event data [22].

We extracted individual-level data on patients with symptomatic or asymptomatic embolism from the included publications and analyzed the risk factors and prognostic indicators of symptomatic air embolism after PTLB. Unfavorable outcomes were defined as (a) patients' survival with sequelae or (b) death. Since it was obvious that asymptomatic patients with air embolism after PTLB had favorable outcomes, we only included symptomatic patients in the analysis of unfavorable outcomes. The symptoms and locations of air embolism were categorized according to whether the brain or heart was involved because these organs play a critical role in patients' outcomes [15-17]. For the univariate analysis, the Student $t$ test for continuous variables and the Pearson chi-square test or Fisher exact test for categorical variables were performed. Subsequently, multivariate logistic regression analysis with backward stepwise selection was performed to identify predictors of symptomatic air embolism and unfavorable outcomes, respectively, using variables with a $p$ value $<0.1$ in the univariate analysis. Backward stepwise selection was conducted with an iterative entry of variables based on the test results $(p<0.05)$, and the removal of variables was based on likelihood ratio statistics with a probability of 0.10 .

A $p$ value of $<0.05$ was considered to indicate a statistically significant difference, and statistical analyses were performed using SPSS version 21.0 (IBM Corp.) and R version 3.6.1 (R Foundation for Statistical Computing).

\section{Results}

\section{Eligible studies and methodological quality}

The initial literature search identified 1756 studies, of which 94 were eligible for the analysis of the incidence of symptomatic air embolism after PTLB or risk factors for symptomatic embolism and unfavorable outcomes. A supplemental search of the bibliographies of the retrieved publications added 7 studies. Finally, 101 studies were included in our analysis (Fig. 1).

In the methodological quality assessment, 19 articles with information on the incidence of symptomatic air embolism [3, $5,6,9,10,14,18,19,23-33]$ and 90 articles with information on the risk factors for symptomatic air embolism and unfavorable outcomes were evaluated $[6,9,14-19,24,26,29$,
34-112], respectively. For the incidence of symptomatic air embolism, all 19 articles were considered high quality, meeting all four items adequately. In the evaluation of risk factors, 81 of 90 articles were judged as high quality, as they satisfied all four items. However, seven case reports did not establish a causality between air embolism and PTLB because the air embolism occurred after repositioning of the biopsy needle to target the lung lesions before firing the biopsy needle [16, $24,39,53,61,89,106]$. Another case report was judged to have insufficient establishment of causality because it described a patient with air embolism just after removal of the coaxial needle stylet [75]. The last case report lacked an adequate ascertainment of exposure and causality between air embolism and PTLB because the patient only had local anesthesia with lidocaine and then presented with symptoms [63].

\section{Incidence of symptomatic air embolism of PTLB}

Nineteen articles were included in the analysis of the incidence of symptomatic air embolism after PTLB, and the pooled incidence was $0.08 \%$ (95\% confidence interval [CI], $0.048-0.128 ; I^{2}=45 \%$ ) (Fig. 2). The subgroup analysis and meta-regression (Table 1) showed that $\mathrm{CT}$ guidance (vs. other modalities; $p=0.002$ ) and study size $<2500$ (vs. $\geq 2500$; $p<0.001)$ were significant factors explaining heterogeneity across studies. There was no evidence of publication bias on a visual evaluation of funnel plots (Fig. 3).

\section{Characteristics of individual patient data}

Details on the clinical, radiological, and biopsy-related information that could be matched to each individual from the 123 patients described in the 90 eligible articles are presented in Table 2.

Seventy-two of the 123 patients $(58.5 \%)$ had underlying diseases, of which cancer was the most common $(36.1 \%, 26$ of 72), followed by chronic obstructive pulmonary disease (COPD) $(23.6 \%, 17$ of 72$)$. Other diseases were asthma, idiopathic pulmonary fibrosis, hypertension, diabetes, and pneumoconiosis.

For 20 patients with lateral decubitus position during the procedure, targeted lungs were non-dependent in 18 patients while 2 patients had unspecified information of whether targeted lung was non-dependent or dependent.

Ninety-eight of the 123 patients (79.7\%) had immediate symptoms or signs during or after PTLB. The most common symptom was loss of consciousness $(42.9 \%, 42$ of 98$)$, followed by cardiac-related symptoms or signs $(32.7 \%, 32$ of 98; chest pain and myocardial infarction) and neurological symptoms or signs $(24.5 \%, 24$ of 98 ; e.g., reduction of sensation, motor weakness, dysarthria, blindness, dysarthria, convulsion). Other symptoms or signs included a change in blood pressure, voiding problems, dyspnea, and hemoptysis. 


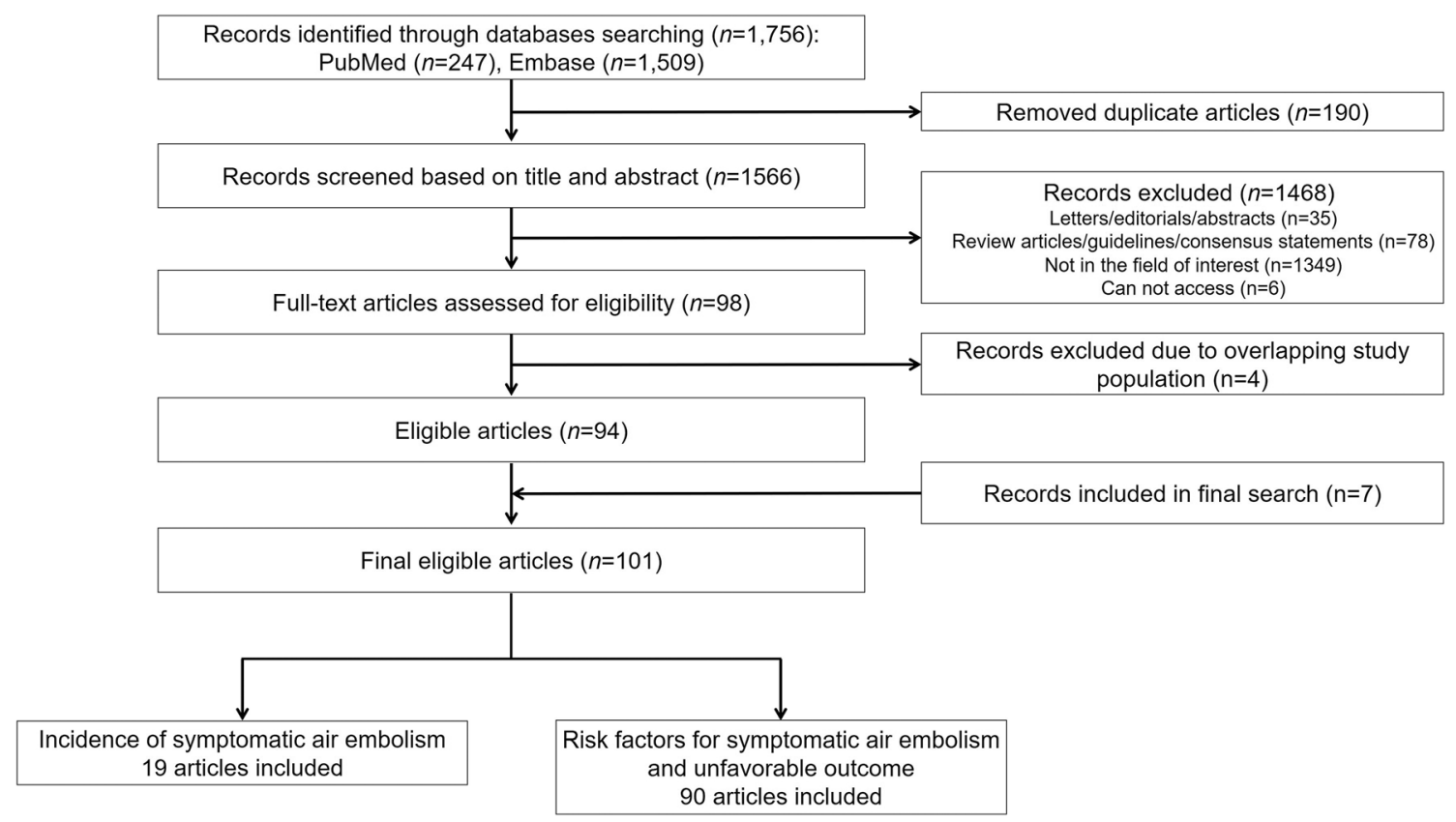

Fig. 1 Flow diagram of the literature search

In terms of the location of the air embolism, 69 patients had air emboli in the coronary arteries or intracranial spaces (59\%, 69 of 117). Other reported locations included the aorta $(21.4 \%, 25$ of 117), left atrium $(17.1 \%, 20$ of 117), left ventricle $(19.7 \%, 23$ of 117), right atrium (1.7\%, 2 of 117), right ventricle $(0.9 \%, 1$ of 117$)$, pulmonary artery $(1.7 \%, 2$ of 117$)$, pulmonary vein $(5.1 \%, 6$ of 117$)$, mesenteric artery $(0.9 \%, 1$ of 117), spinal artery $(0.9 \%, 1$ of 117$)$, and the systematic venous system including the superior vena cava and subclavian vein $(0.9 \%, 1$ of 117$)$.

In regard to patients' outcomes, 66 of the 98 patients (67.3\%) with symptomatic embolism survived without any sequelae, whereas $11(11.2 \%)$ and $21(21.5 \%)$ patients survived with sequelae and died, respectively. Therefore, 32 of 98 patients (32.7\%) with symptomatic embolism were considered to have an unfavorable outcome.

\section{Risk factors for symptomatic air embolism after PTLB}

In the analysis of risk factors for symptomatic air embolism after PTLB, 117 patients were included after the exclusion of 6 patients whose symptoms or signs were not described in the corresponding studies. In the univariate analysis, a younger age than 65 years $(p=0.014)$, aspiration biopsy rather than core biopsy $(p=0.04), \mathrm{a} \geq 19$-gauge needle $(p=0.004)$, and location of the air embolism in the coronary arteries or intracranial space $(p<0.001)$ showed significant associations with symptomatic air embolism while factors with $p$ values between 0.05 and 0.1 were the presence of an underlying disease $(p=0.091)$ and supine position rather than lateral decubitus position $(p=0.094)$ (Table 3). In a multivariate analysis of 93 patients who had clear information on the above characteristics, the presence of an underlying disease (odds ratio $[\mathrm{OR}]=5.939 ; 95 \%$ confidence

Table 1 Result of subgroup analysis and meta-regression of incidence of symptomatic air embolism after percutaneous transthoracic lung biopsy

\begin{tabular}{|c|c|c|c|c|c|c|c|}
\hline \multirow[t]{2}{*}{ Covariate } & & \multirow[t]{2}{*}{ Number of studies } & \multicolumn{2}{|l|}{ Subgroup analysis } & \multicolumn{3}{|l|}{ Meta-regression } \\
\hline & & & $\begin{array}{l}\text { Events per } 1000 \text { patients } \\
{[95 \% \text { confidence interval] }]^{*}}\end{array}$ & $I^{2}(\%)$ & Beta $[95 \%$ confidence interval] & $p$ value & $I^{2 *}(\%)$ \\
\hline \multirow[t]{2}{*}{ Guidance modality } & CT guidance & 13 & $1.25[0.82,1.89]$ & 11.9 & 0 & 0.002 & 6.9 \\
\hline & Other modalities & 6 & $0.24[0.11,0.50]$ & 0 & $-1.66[-2.62,-0.7]$ & & \\
\hline \multirow[t]{2}{*}{ Study size } & $\geq 2500$ & 4 & $0.34[0.19,0.58]$ & 0 & 0 & $<0.001$ & 0.0 \\
\hline & $<2500$ & 15 & $1.55[1.03,2.33]$ & 0 & $1.53[0.8,2.26]$ & & \\
\hline \multirow[t]{2}{*}{ Publication year } & After 2000 & 16 & $0.87[0.53,1.43]$ & 45 & 0 & 0.171 & 47.6 \\
\hline & Before 2000 & 3 & $0.18[0.03,1.30]$ & 0 & $-1.71[-4.22,0.81]$ & & \\
\hline
\end{tabular}

*Percentage of residual heterogeneity unexplained by accounted factors in the model 
Fig. 2 Forest plot for incidence of symptomatic air embolism after percutaneous transthoracic lung biopsy (events per 1000 patients)
Study

Roy DC et al, 1974

Sinner WN, 1979

Lucidarme O et al, 1998

Tomiyama N et al, 2006

Ibukuro K et al, 2009

Kuo HL et al, 2010

Hare SS et al, 2011

Lee SM et al, 2013

Ishii H et al, 2014

Szlezak P et al, 2014

Pando Sandoval A et al, 2015

Sun C et al, 2015

Takeshita J et al, 2015

Azrumelashvili T et al, 2016

Glodny B et al, 2017

Jang $\mathrm{H}$ et al, 2019

Valerie Monnin-Bares et al, 2019

Yoon SH et al, 2019

SHI HE LIU et al, 2020

Random effects model

Heterogeneity: $I^{2}=45 \%$

\section{Events Total}

interval $[\mathrm{CI}]=1.029-34.279 ; p=0.046)$, use of a $\geq 19$-gauge needle $(\mathrm{OR}=10.046,95 \% \mathrm{CI}=1.103-91.469 ; p=0.041)$, and location of the air embolism in the coronary arteries or intracranial spaces $(\mathrm{OR}=19.871 ; 95 \% \mathrm{CI}=2.725-14.925 ; p=0.003)$ were found to be significant risk factors. Regarding the underlying disease, cancer, COPD, hypertension, diabetes, idiopathic pulmonary fibrosis, and asthma were associated with symptomatic air embolism in descending order.

\section{Prognostic indicators for unfavorable outcomes of air embolism after PTLB}

In the analysis of unfavorable outcomes in patients with symptomatic air embolism, aspiration biopsy rather than core

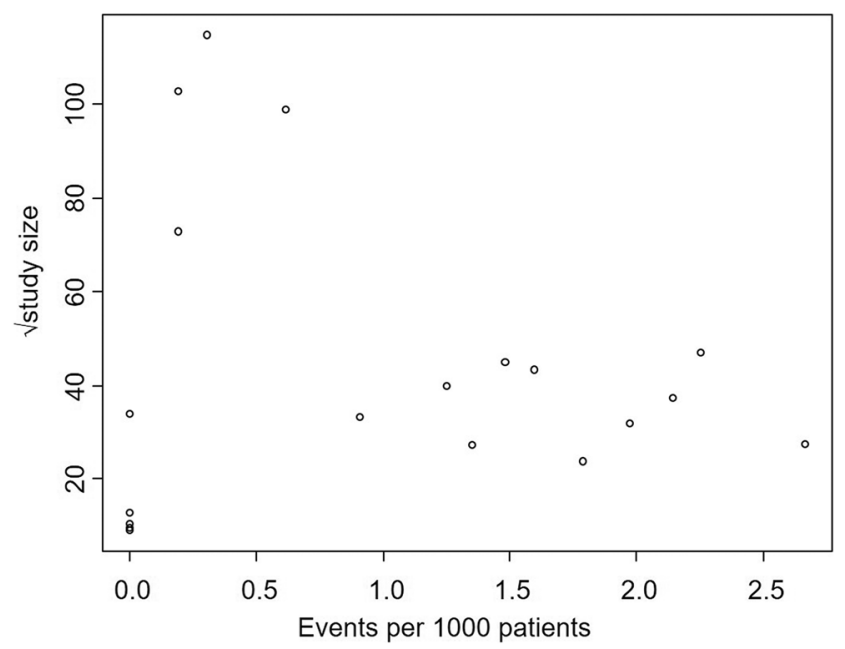

Fig. 3 Funnel plot of included studies evaluating incidence of symptomatic air embolism after percutaneous transthoracic lung biopsy (events per 1000 patients)

$\begin{array}{rr}0 & 80 \\ 1 & 5300 \\ 0 & 91 \\ 6 & 9783 \\ 3 & 1400 \\ 1 & 741 \\ 4 & 13206 \\ 0 & 1153 \\ 5 & 2216 \\ 0 & 162 \\ 2 & 1600 \\ 1 & 1100 \\ 2 & 750 \\ 0 & 106 \\ 3 & 1878 \\ 2 & 1014 \\ 1 & 559 \\ 2 & 10568 \\ 3 & 2026\end{array}$

Events per 1000 patients

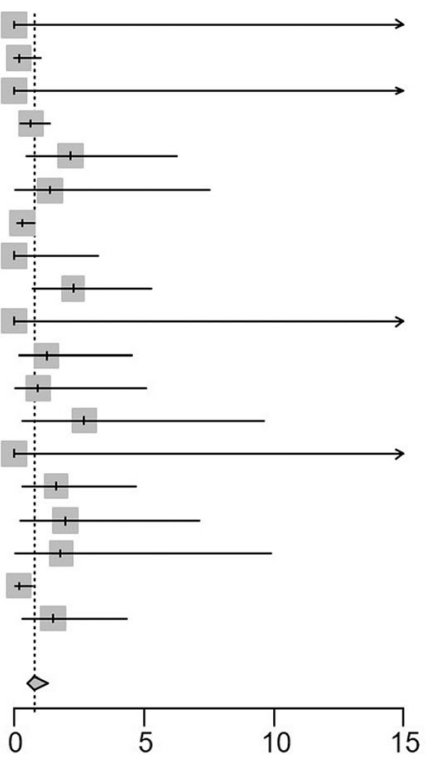

Incidence $[95 \% \mathrm{Cl}]$

$0.00[0.00 ; 45.06]$

$0.19[0.00 ; 1.05]$

$0.00[0.00 ; 39.73]$

$0.61[0.23 ; 1.33]$

$2.14[0.44 ; 6.25]$

$1.35[0.03 ; 7.50]$

$0.30[0.08 ; 0.78]$

$0.00[0.00 ; 3.19]$

$2.26[0.73 ; 5.26]$

$0.00[0.00 ; 22.51]$

$1.25[0.15 ; 4.51]$

0.91 [0.02; 5.05]

$2.67[0.32 ; 9.60]$

$0.00[0.00 ; 34.20]$

$1.60[0.33 ; 4.66]$

$1.97[0.24 ; 7.11]$

$1.79[0.05 ; 9.93]$

$0.19[0.02 ; 0.68]$

$1.48[0.31 ; 4.32]$

$0.78[0.48 ; 1.28]$ biopsy ( $p=0.013)$, loss of consciousness as an immediate symptom $(p=0.021)$, and location of the air embolism in the coronary arteries or intracranial spaces $(p=0.001)$ were found to be significant risk factors in the univariate analysis, while factors with $p$ values between 0.05 and 0.1 were a younger age than 65 years $(p=0.075)$, lesion size of $2 \mathrm{~cm}$ or larger $(p=$ $0.093)$, no use of the coaxial technique $(p=0.087)$, and no application of the Trendelenburg position $(p=0.084)$ (Table 4). Excluding the factors of lesion size and use of the coaxial technique because of the large number of patients with missing data on these factors, a multivariate analysis could be performed of 90 patients. In this analysis, aspiration biopsy rather than core biopsy $(\mathrm{OR}=3.302 ; 95 \% \mathrm{CI}=1.149-9.492$; $p=0.027$ ) and location of the air embolism in the coronary arteries or intracranial spaces $(\mathrm{OR}=5.173 ; 95 \% \mathrm{CI}=1.309$ 20.447; $p=0.019$ ) were significant risk factors for unfavorable outcomes.

\section{Discussion}

The commonly accepted incidence of air embolism, focusing on symptomatic patients, has been reported to be 0.02 to $0.07 \%$ [12-14], and our finding of a pooled incidence of symptomatic air embolism after PTLB of $0.08 \%$ is similar to the incidence reported in previous studies. However, some recent studies have reported that the incidence of air embolism after PTLB ranged from 0.21 to $3.8 \%$ based on the inclusion of asymptomatic patients with extensive surveys of postbiopsy CT examinations $[6,8,9,11,19,24]$. Because of the major difference between the incidence of asymptomatic and symptomatic embolism unveiled in prior studies, we only pooled studies dealing with symptomatic air embolism. 
Table 2 Baseline clinical, radiological and percutaneous transthoracic lung biopsy-related characteristics of 123 patients

\begin{tabular}{|c|c|c|c|}
\hline Age (years) & $64.2 \pm 11.6($ range, $25-85)$ & $\begin{array}{l}\text { Distance between pleura } \\
\text { and target lesion }\end{array}$ & \\
\hline$\geq 65$ years & $56(45.5 \%)$ & $\geq 1 \mathrm{~cm}$ & $16(13 \%)$ \\
\hline$<65$ years & $66(53.7 \%)$ & $<1 \mathrm{~cm}$ & $8(6.5 \%)$ \\
\hline Not specified & $1(0.8 \%)$ & Not specified & $99(80.5 \%)$ \\
\hline Sex & & Biopsy needle gauge & \\
\hline Men & $84(68.3 \%)$ & $\geq 20$ gauge & $55(44.7 \%)$ \\
\hline Women & $39(31.7 \%)$ & $<20$ gauge & $52(42.3 \%)$ \\
\hline Underlying disease & & Not specified & $16(13 \%)$ \\
\hline Yes & $72(58.5 \%)$ & Coaxial technique & \\
\hline No & $40(32.5 \%)$ & Yes & $68(55.3 \%)$ \\
\hline Not specified & $11(8.9 \%)$ & No & $37(30.1 \%)$ \\
\hline Mechanical ventilation & & Not specified & $18(14.6 \%)$ \\
\hline Yes & $6(4.9 \%)$ & Cough & \\
\hline No & $106(86.2 \%)$ & No & $74(60.2 \%)$ \\
\hline Not specified & $11(8.9 \%)$ & Yes & $45(36.6 \%)$ \\
\hline $\begin{array}{l}\text { Long diameter of target } \\
\text { lesion }(\mathrm{cm})\end{array}$ & $2.3 \pm 1.6($ range, $0.5-11) ;$ Median 2 & Not specified & $4(3.3 \%)$ \\
\hline$\geq 2 \mathrm{~cm}$ & $42(34.1 \%)$ & Symptom or sign & \\
\hline$<2 \mathrm{~cm}$ & $40(32.5 \%)$ & Yes & $98(79.7 \%)$ \\
\hline Not specified & $41(33.3 \%)$ & No & $19(15.4 \%)$ \\
\hline Target lesion type & & Not specified & $6(4.9 \%)$ \\
\hline Solid or consolidation & $93(75.6 \%)$ & Cardiac symptom & \\
\hline Ground-glass opacity & $8(6.5 \%)$ & Yes & $32(26.0 \%)$ \\
\hline Not specified & $22(17.9 \%)$ & No (other symptoms) & $66(53.7 \%)$ \\
\hline Cavitary/cystic change & & Not specified & $25(20.3 \%)$ \\
\hline Yes & $17(13.8 \%)$ & Loss of consciousness & \\
\hline No & $84(68.3 \%)$ & Yes & $42(34.1 \%)$ \\
\hline Not specified & $22(17.9 \%)$ & No (other symptoms) & $56(45.5 \%)$ \\
\hline Lobar location & & Not specified & $25(20.3 \%)$ \\
\hline $\begin{array}{l}\text { RUL, RML, RLL, LUL, } \\
\text { LLL, not specified }\end{array}$ & $\begin{array}{c}17(13.8 \%), 10(8.1 \%), 28(22.8 \%), 13 \\
(10.6 \%), 33(26.8 \%), 22(17.9 \%)\end{array}$ & Location of air embolism & \\
\hline Upper and middle lobe & $42(34.1 \%)$ & $\begin{array}{r}\text { Coronary arteries or } \\
\text { intracranial space }\end{array}$ & $69(56.1 \%)$ \\
\hline Lower lobe & $67(54.5 \%)$ & Others & $48(39 \%)$ \\
\hline Not specified & $14(11.9 \%)$ & Not specified & $6(4.9 \%)$ \\
\hline Guidance modality & & $\begin{array}{l}\text { Hyperbaric oxygen } \\
\text { treatment }\end{array}$ & \\
\hline $\mathrm{CT}$ & $112(91.1 \%)$ & Yes & $39(31.7 \%)$ \\
\hline Others & $8(6.5 \%)$ & No & $82(66.7 \%)$ \\
\hline Not specified & $3(2.4 \%)$ & Not specified & $2(1.6 \%)$ \\
\hline Biopsy methods & & Trendelenburg position & \\
\hline Core biopsy & $92(74.8 \%)$ & Yes & $30(24.4 \%)$ \\
\hline Aspiration biopsy & $27(22 \%)$ & No & $80(65 \%)$ \\
\hline Not specified & $4(3.2 \%)$ & Not specified & $13(10.6 \%)$ \\
\hline Patient position & & Other complication & \\
\hline Supine & $31(25.2 \%)$ & Yes & $65(52.8 \%)$ \\
\hline Prone & $53(43.1 \%)$ & No & $40(32.5 \%)$ \\
\hline Lateral decubitus & $20(16.3 \%)$ & Not specified & $18(14.6 \%)$ \\
\hline Not specified & $19(15.4 \%)$ & Outcome* & \\
\hline Maximum needle gauge & & $\begin{array}{l}\text { Survival without any } \\
\text { sequela }\end{array}$ & $\begin{array}{l}89(72.3 \%) \\
\quad[66,67.3 \%]\end{array}$ \\
\hline$\geq 19$ gauge & $65(52.8 \%)$ & Survival with sequela & $\begin{array}{c}12(9.8 \%)[11 \\
11.2 \%]\end{array}$ \\
\hline$<19$ gauge & $42(34.1 \%)$ & Death & $\begin{array}{l}22(17.9 \%) \\
{[21,21.5 \%]}\end{array}$ \\
\hline Not specified & $16(13 \%)$ & & \\
\hline
\end{tabular}

*Number and percentage of outcome in patients with symptomatic air embolism $(n=98)$ are suggested in each bracket
In the subgroup analysis and meta-regression analysis, studies that only analyzed CT-guided PTLB had significantly more events than studies using other modalities (e.g., fluoroscopy and ultrasonography). The finding is unsurprising because air embolism could be detected directly with postbiopsy CT surveillance in studies of CT-guided PTLB. To support this inference, the majority of cases in those studies included cases of air embolism located in the heart, coronary arteries, aorta, and pulmonary vein, which are in the scan range of chest CT. Study size was another significant factor contributed to the heterogeneity, as the average incidence in studies that enrolled a small number of patients was higher 
Table 3 Univariate analysis and multivariate logistic regression analysis to investigate risk factors for symptomatic air embolism after percutaneous transthoracic needle biopsy in 117 patients

\begin{tabular}{|c|c|c|c|c|c|c|}
\hline & \multicolumn{3}{|c|}{ Univariate analysis } & \multicolumn{3}{|c|}{ Multivariate analysis $(n=93)$} \\
\hline & $\begin{array}{l}\text { Odds } \\
\text { ratio }\end{array}$ & $\begin{array}{l}95 \% \\
\text { confidence } \\
\text { interval }\end{array}$ & $p$ value & $\begin{array}{l}\text { Odds } \\
\text { ratio }\end{array}$ & $\begin{array}{l}95 \% \\
\text { confidence } \\
\text { interval }\end{array}$ & $p$ value \\
\hline $\begin{array}{l}\text { Age }<65 \text { years (vs. } \\
\geq 65 \text { years) }\end{array}$ & 3.77 & $1.246,11.408$ & 0.014 & & & \\
\hline Male (vs. female) & 1.73 & $0.631,4.745$ & 0.283 & & & \\
\hline Underlying disease (vs. none) & 2.333 & $0.858,6.343$ & 0.091 & 5.939 & $1.029,34.279$ & 0.046 \\
\hline $\begin{array}{l}\text { Mechanical ventilation (vs. } \\
\text { none) }\end{array}$ & 1.023 & $0.113,9.286$ & 1.000 & & & \\
\hline $\begin{array}{l}\text { Diameter of target lesion } \geq 2 \\
\quad(\text { vs. }<2 \mathrm{~cm})\end{array}$ & 0.92 & $0.312,2.709$ & 0.879 & & & \\
\hline $\begin{array}{l}\text { Solid lesion (vs. subsolid } \\
\text { lesion) }\end{array}$ & 2.888 & $0.626,13.326$ & 0.17 & & & \\
\hline $\begin{array}{l}\text { Cavitary/cystic change } \\
\text { (vs. none) }\end{array}$ & 1.379 & $0.279,6.805$ & 1.000 & & & \\
\hline $\begin{array}{l}\text { Lower lobar location } \\
\text { (vs. upper or middle lobe) }\end{array}$ & 1.742 & $0.626,4.85$ & 0.285 & & & \\
\hline $\begin{array}{l}\text { CT-guided biopsy (vs. other } \\
\text { modality) }\end{array}$ & 1.211 & $1.111,1.32$ & 0.587 & & & \\
\hline $\begin{array}{l}\text { Aspiration biopsy (vs. core } \\
\text { biopsy) }\end{array}$ & 6.882 & $0.874,52.202$ & 0.04 & & & \\
\hline $\begin{array}{l}\text { Pleura to target lesion } \geq 1 \mathrm{~cm} \\
\quad(\text { vs. }<1 \mathrm{~cm})\end{array}$ & 0.9 & $0.133,6.08$ & 1.000 & & & \\
\hline Needle gauge $\geq 19($ vs. $<19)$ & 7.442 & $1.609,34.427$ & 0.004 & 10.046 & $1.103,91.469$ & 0.041 \\
\hline $\begin{array}{l}\text { Supine position (vs. prone } \\
\text { position) }\end{array}$ & 0.456 & $0.134,1.548$ & 0.265 & & & \\
\hline $\begin{array}{l}\text { Supine position (vs. lateral } \\
\text { decubitus position) }\end{array}$ & 6.175 & $0.752,50.729$ & 0.094 & & & \\
\hline No coaxial technique (vs. use) & 0.558 & $0.197,1.583$ & 0.269 & & & \\
\hline Cough (vs. none) & 0.797 & $0.288,2.205$ & 0.662 & & & \\
\hline $\begin{array}{l}\text { Location of air embolism in } \\
\text { coronary arteries or } \\
\text { intracranial spaces } \\
\text { (vs. other location) }\end{array}$ & 18.371 & $3.995,84.482$ & $<0.001$ & 19.871 & $2.725,144.925$ & 0.003 \\
\hline
\end{tabular}

$p$ values of statistically significant variables are in italics than that of large-scale studies. It is speculated that when air embolism occurs after PTLB in a small-scale study, its incidence may be estimated as much higher than would be the case in a large-scale study.

Since prompt recognition of air embolism is critical for optimizing patients' clinical course $[6,18]$, it is paramount to investigate the risk factors of symptomatic air embolism. We found the presence of an underlying disease, larger gauge of the biopsy needle, and location of the air embolism in the coronary arteries or intracranial spaces were predictive factors for symptomatic air embolism. COPD was the most common underlying disease (23.6\% of the included patients), which may be explained by the fact that COPD can result in extended exposure of the pulmonary vessel lumen to the airway, thereby increasing the chance of air bubbles entering the bloodstream [56]. The relationship of needle gauge with air embolism after PTLB is controversial, because a number of cases of air embolism occurred even when a small needle was used [8, $72,77,78]$. To explain the association found in our study, it is speculated that once an air embolism occurs, the use of a large needle results in higher chance of a sufficiently large air bolus entering the bloodstream and causing symptoms [9]. Finally, the presence of an air embolism in the coronary or cerebral arteries was linked to a severely deteriorated prognosis, with outcomes including myocardial infarction and permanent neurological deficits $[6,61,85,111]$. Concordant with prior studies, location of the air embolism in the coronary arteries or intracranial spaces was a significant predictor of symptomatic air embolism.

Of note, we found that $32.7 \%$ ( 32 of 98 ) of symptomatic patients with air embolism had unfavorable outcomes. Of those 32 patients, 21 died and 11 survived, but had neurological sequelae. Our results suggest that two-thirds of patients with symptoms or signs eventually survive without any sequelae. The use of aspiration biopsy rather than core biopsy and the presence of the air embolism in coronary arteries or intracranial spaces were significant prognostic indicators for unfavorable outcomes in our study. We suggest that aspiration 
Table 4 Univariate analysis and multivariate logistic regression analysis to investigate prognostic indicators for unfavorable outcome in 98 patients with symptomatic air embolism after percutaneous transthoracic needle biopsy

\begin{tabular}{|c|c|c|c|c|c|c|}
\hline & \multicolumn{3}{|c|}{ Univariate analysis } & \multicolumn{3}{|c|}{ Multivariate analysis $(n=90)$} \\
\hline & $\begin{array}{l}\text { Odds } \\
\text { ratio }\end{array}$ & $\begin{array}{l}95 \% \text { confidence } \\
\text { interval }\end{array}$ & $\begin{array}{l}p \\
\text { value }\end{array}$ & $\begin{array}{l}\text { Odds } \\
\text { ratio }\end{array}$ & $\begin{array}{l}95 \% \text { confidence } \\
\text { interval }\end{array}$ & $\begin{array}{l}p \\
\text { value }\end{array}$ \\
\hline Age $<65$ years (vs. $\geq 65$ years) & 2.263 & $0.911,5.621$ & 0.075 & & & \\
\hline Male (vs. female) & 0.889 & $0.355,2.227$ & 0.802 & & & \\
\hline Underlying disease (vs. none) & 1.245 & $0.5,3.1$ & 0.638 & & & \\
\hline Mechanical ventilation (vs. none) & 3.214 & $0.508,20.332$ & 0.329 & & & \\
\hline Diameter of target lesion $\geq 2$ (vs. $<2 \mathrm{~cm}$ ) & 2.779 & $0.823,9.379$ & 0.093 & & & \\
\hline Solid lesion (vs. subsolid lesion) & 0.765 & $0.12,4.866$ & 1.000 & & & \\
\hline Cavitary/cystic change (vs. none) & 1.725 & $0.529,5.622$ & 0.362 & & & \\
\hline Lower lobar location (vs. upper or middle lobe) & 0.636 & $0.245,1.653$ & 0.352 & & & \\
\hline CT-guided biopsy (vs. other modality) & 0.951 & $0.165,5.494$ & 0.955 & & & \\
\hline Aspiration biopsy (vs. core biopsy) & 3.25 & $1.255,8.414$ & 0.013 & 3.302 & $1.149,9.492$ & 0.027 \\
\hline Pleura to target lesion $\geq 1 \mathrm{~cm}(\mathrm{vs} .<1 \mathrm{~cm})$ & 1.0 & $0.141,7.099$ & 1.000 & & & \\
\hline Needle gauge $\geq 19$ (vs. < 19) & 1.391 & $0.548,3.528$ & 0.486 & & & \\
\hline Supine position (vs. prone position) & 0.715 & $0.261,1.96$ & 0.514 & & & \\
\hline Supine position (vs. lateral decubitus position) & 1.63 & $0.499,5.324$ & 0.417 & & & \\
\hline No coaxial technique (vs. use) & 2.357 & $0.872,6.374$ & 0.087 & & & \\
\hline Cough (vs. none) & 1.644 & $0.692,3.91$ & 0.259 & & & \\
\hline Cardiac symptom (vs. no cardiac symptom) & 2.074 & $0.857,5.02$ & 0.103 & & & \\
\hline Loss of consciousness (vs. no loss of consciousness) & 2.732 & $1.147,6.511$ & 0.021 & 2.512 & $0.903,6.985$ & 0.078 \\
\hline $\begin{array}{l}\text { Location of air embolism in coronary arteries or intracranial spaces (vs. } \\
\text { other location) }\end{array}$ & 7.123 & $1.971,25.747$ & 0.001 & 5.173 & $1.309,20.447$ & 0.019 \\
\hline Hyperbaric oxygen treatment (vs. none) & 1.574 & $0.653,3.792$ & 0.311 & & & \\
\hline No Trendelenburg position (vs. application) & 2.571 & $0.862,7.669$ & 0.084 & & & \\
\hline Other complication & 1.143 & $0.472,2.767$ & 0.767 & & & \\
\hline
\end{tabular}

$p$ values of statistically significant variables are in italics

biopsy may cause a large air bolus due to the back-and-forth technique inherently involved in this procedure, which results in a high likelihood of air entering the bloodstream. As was described above, the organ involved in air embolism is a critical factor for patients' symptoms and outcomes, and it is therefore natural for location of the air embolism in the coronary arteries and intracranial spaces to be a significant predictor of unfavorable outcomes.

There has been controversy about application of the Trendelenburg position for patients with air embolism [61, 90, 111, 113-115]. According to some authorities, the Trendelenburg position is only appropriate for cases of venous air embolism, as it keeps the air bolus in the right ventricular cavity $[114,115]$. Nevertheless, our systematic review revealed that patients who had been placed in the Trendelenburg position for air embolism tended to have favorable outcomes ( 20 of 25 patients, $p=0.084$ in the univariate analysis) and most of these patients had arterial air embolism (23 of 25 patients). Although application of the Trendelenburg position did not show significance in the multivariate analysis, this tendency of the Trendelenburg position to be associated with favorable outcomes should be investigated in further studies.

Two main limitations should be stated. Most importantly, this study comprised mostly case reports or series due to the rarity of air embolism after PTLB, and therefore, the certainty of the evidence could be low [20]. For instance, hyperbaric oxygen therapy is believed to be a mainstay treatment for air embolism because it helps reduce bubble volume, biochemical reactions at the blood-gas interface that result in hemostasis, and endothelial damage $[69,79,90]$. Despite its proven usefulness, it was not associated with patients' outcomes in our study. Second, we did not receive clarifications on missing or unreported data in several cases. Consequentially, relatively few patients were included in the analysis of risk factors, which might have caused potential bias and limited our results.

In conclusion, the pooled incidence of symptomatic air embolism after PTLB was $0.08 \%$, and one-third of cases had sequelae or died. Symptomatic air embolism was more frequent in patients with an underlying disease $(p=0.046)$, with the use of $\mathrm{a} \geq 19$-gauge needle $(p=0.041)$, and when the air 
embolism was located in the coronary arteries or intracranial spaces $(p=0.003)$. The use of aspiration biopsy rather than core biopsy $(p=0.027)$ and location of the air embolism in the coronary arteries or intracranial spaces $(p=0.019)$ were independent prognostic indicators of unfavorable outcomes.

Funding The authors state that this work has not received any funding.

\section{Compliance with ethical standards}

Guarantor The scientific guarantor of this publication is Soon Ho Yoon.

Conflict of interest The authors of this manuscript declare no relationships with any companies whose products or services may be related to the subject matter of the article.

Statistics and biometry One of the authors has significant statistical expertise (Hyunsook Hong).

Informed consent Written informed consent was not required because this study is a systematic review and pooled analysis of the literature.

Ethical approval Institutional Review Board approval was not required because this study is a systematic review and pooled analysis of the literature.

Study subjects or cohorts overlap This study is a systematic review of the literature and pooled analysis of all their patients.

\author{
Methodology \\ - retrospective \\ - diagnostic or prognostic study \\ - multicenter study
}

Open Access This article is licensed under a Creative Commons Attribution 4.0 International License, which permits use, sharing, adaptation, distribution and reproduction in any medium or format, as long as you give appropriate credit to the original author(s) and the source, provide a link to the Creative Commons licence, and indicate if changes were made. The images or other third party material in this article are included in the article's Creative Commons licence, unless indicated otherwise in a credit line to the material. If material is not included in the article's Creative Commons licence and your intended use is not permitted by statutory regulation or exceeds the permitted use, you will need to obtain permission directly from the copyright holder. To view a copy of this licence, visit http://creativecommons.org/licenses/by/4.0/.

\section{References}

1. Rivera MP, Mehta AC, Wahidi MM (2013) Establishing the diagnosis of lung cancer: diagnosis and management of lung cancer: American College of Chest Physicians evidence-based clinical practice guidelines. Chest 143:e142S-e165S

2. Manhire A, Charig M, Clelland C et al (2003) Guidelines for radiologically guided lung biopsy. Thorax 58:920-936

3. Lee SM, Park CM, Lee KH, Bahn YE, Kim JI, Goo JM (2013) Carm cone-beam CT-guided percutaneous transthoracic needle biopsy of lung nodules: clinical experience in 1108 patients. Radiology 271:291-300
4. Hiraki T, Mimura H, Gobara H et al (2009) CT fluoroscopyguided biopsy of 1,000 pulmonary lesions performed with 20 gauge coaxial cutting needles: diagnostic yield and risk factors for diagnostic failure. Chest 136:1612-1617

5. Yoon SH, Park CM, Lee KH et al (2019) Analysis of complications of percutaneous transthoracic needle biopsy using CTguidance modalities in a multicenter cohort of 10568 biopsies. Korean J Radiol 20:323-331

6. Jang H, Rho JY, Suh YJ, Jeong YJ (2019) Asymptomatic systemic air embolism after CT-guided percutaneous transthoracic needle biopsy. Clin Imaging 53:49-57

7. Boskovic T, Stanic J, Pena-Karan S et al (2014) Pneumothorax after transthoracic needle biopsy of lung lesions under CT guidance. J Thorac Dis 6:S99-S107

8. Hiraki T, Fujiwara H, Sakurai J et al (2007) Nonfatal systemic air embolism complicating percutaneous CT-guided transthoracic needle biopsy: four cases from a single institution. Chest 132: 684-690

9. Ishii H, Hiraki T, Gobara H et al (2014) Risk factors for systemic air embolism as a complication of percutaneous CT-guided lung biopsy: multicenter case-control study. Cardiovasc Intervent Radiol 37:1312-1320

10. Glodny B, Schonherr E, Freund MC et al (2017) Measures to prevent air embolism in transthoracic biopsy of the lung. AJR Am J Roentgenol 208:W184-W191

11. Freund MC, Petersen J, Goder KC, Bunse T, Wiedermann F, Glodny B (2012) Systemic air embolism during percutaneous core needle biopsy of the lung: frequency and risk factors. BMC Pulm Med. https://doi.org/10.1186/1471-2466-12-2

12. Sinner WN (1976) Complications of percutaneous transthoracic needle aspiration biopsy. Acta Radiol Diagn (Stockh) 17:813-828

13. Richardson CM, Pointon KS, Manhire AR, Macfarlane JT (2002) Percutaneous lung biopsies: a survey of UK practice based on 5444 biopsies. Br J Radiol 75:731-735

14. Tomiyama N, Yasuhara Y, Nakajima Y et al (2006) CT-guided needle biopsy of lung lesions: a survey of severe complication based on 9783 biopsies in Japan. Eur J Radiol 59:60-64

15. Cheng HM, Chiang KH, Chang PY et al (2010) Coronary artery air embolism: a potentially fatal complication of CT-guided percutaneous lung biopsy. Br J Radiol 83:e83-e85

16. Tolly TL, Fedlmeier JE, Czarnecki D (1988) Air embolism complicating percutaneous lung biopsy. AJR Am J Roentgenol 150: $555-556$

17. Kodama F, Ogawa T, Hashimoto M, Tanabe Y, Suto Y, Kato T (1999) Fatal air embolism as a complication of CT-guided needle biopsy of the lung. J Comput Assist Tomogr 23:949-951

18. Hare SS, Gupta A, Goncalves AT, Souza CA, Matzinger F, Seely JM (2011) Systemic arterial air embolism after percutaneous lung biopsy. Clin Radiol 66:589-596

19. Ibukuro K, Tanaka R, Takeguchi T, Fukuda H, Abe S, Tobe K (2009) Air embolism and needle track implantation complicating CT-guided percutaneous thoracic biopsy: single-institution experience. AJR Am J Roentgenol 193:W430-W436

20. Murad MH, Sultan S, Haffar S, Bazerbachi F (2018) Methodological quality and synthesis of case series and case reports. BMJ Evid Based Med 23:60-63

21. Stijnen T, Hamza TH, Özdemir P (2010) Random effects metaanalysis of event outcome in the framework of the generalized linear mixed model with applications in sparse data. Stat Med 29:3046-3067

22. Hunter JP, Saratzis A, Sutton AJ, Boucher RH, Sayers RD, Bown MJ (2014) In meta-analyses of proportion studies, funnel plots were found to be an inaccurate method of assessing publication bias. J Clin Epidemiol 67:897-903 
23. Roy DC, Mehrotra ML (1974) An evaluation of percutaneous trephine biopsy in the diagnosis of lung diseases. Am Rev Respir Dis 110:133-136

24. Kuo HL, Cheng L, Chung TJ (2010) Systemic air embolism detected during percutaneous transthoracic needle biopsy: report of two cases and a proposal for a routine postprocedure computed tomography scan of the aorto-cardiac region. Clin Imaging 34:5356

25. Lucidarme O, Howarth N, Finet JF, Grenier PA (1998) Intrapulmonary lesions: percutaneous automated biopsy with a detachable, 18-gauge, coaxial cutting needle. Radiology 207: 759-765

26. Pando Sandoval A, Ariza Prota MA, Garcia Clemente M, Prieto A, Fole Vazquez D, Casan P (2015) Air embolism: a complication of computed tomography-guided transthoracic needle biopsy. Respirol Case Rep 3:48-50

27. Azrumelashvili T, Mizandari M, Dundua T (2016) Imaging guided percutaneal core biopsy of pulmonary and pleural masses technique and complications. Georgian Med News 250:25-33

28. Sinner WN (1979) Pulmonary neoplasms diagnosed with transthoracic needle biopsy. Cancer 43:1533-1540

29. Sun C, Bian J, Lai S, Li X (2015) Systemic air embolism as a complication of CT-guided percutaneous core needle lung biopsy: a case report and review of the literature. Exp Ther Med 10:11571160

30. Szlezak P, Śrutek E, Gorycki T, Kowalewski J, Studniarek M (2014) Core-needle biopsy under CT fluoroscopy guidance and fine-needle aspiration cytology: comparison of diagnostic yield in the diagnosis of lung and mediastinum tumors. Analysis of frequency and types of complications. Pol J Radiol 79:175-180

31. Takeshita J, Masago K, Kato R et al (2015) CT-guided fine-needle aspiration and core needle biopsies of pulmonary lesions: a singlecenter experience with 750 biopsies in Japan. AJR Am J Roentgenol 204:29-34

32. Monnin-Bares V, Chassagnon G, Vernhet-Kovacsik H et al (2019) Systemic air embolism depicted on systematic whole thoracic $\mathrm{CT}$ acquisition after percutaneous lung biopsy: incidence and risk factors. Eur J Radiol 117:26-32

33. Liu SH, Fu Q, Yu HL et al (2020) A retrospective analysis of the risk factors associated with systemic air embolism following percutaneous lung biopsy. Exp Ther Med 19:347-352

34. Aberle DR, Gamsu G, Golden JA (1987) Fatal systemic arterial air embolism following lung needle aspiration. Radiology 165:351353

35. Al-Ali WM, Browne T, Jones R (2012) A case of cranial air embolism after transthoracic lung biopsy. Am J Respir Crit Care Med 186:1193-1195

36. April D, Sandow T, Scheibal J, Devun D, Kay D (2017) Left atrial air embolism following computed tomography-guided lung biopsy. Ochsner J 17:141-143

37. Arnold BW, Zwiebel WJ (2002) Percutaneous transthoracic needle biopsy complicated by air embolism. AJR Am J Roentgenol 178:1400-1402

38. Beliaev AM, Milne D, Sames C, O'Brien B, Ramanathan T (2019) Massive arteriovenous air embolism after computed tomography-guided lung tumour biopsy. ANZ J Surg 89:434-436

39. Bhatia $S$ (2009) Systemic air embolism following CT-guided lung biopsy. J Vasc Interv Radiol 20:709-711

40. Bou-Assaly W, Pernicano P, Hoeffner E (2010) Systemic air embolism after transthoracic lung biopsy: a case report and review of literature. World J Radiol 2:193-196

41. Kooblall M, Lane SJ, Moloney E (2015) 'Life saving positioning' in patients with air embolism. Ir Med J 108:318

42. Chakravarti R, Singh V, Isaac R, John MJ (2004) Fatal paradoxical pulmonary air embolism complicating percutaneous computed tomography-guided needle biopsy of the lung. Australas Radiol 48:204-206

43. Chang HC, Yang MC (2018) Systemic air embolism after percutaneous computed tomography-guided lung biopsy due to a kink in the coaxial biopsy system: a case report. BMC Med Imaging 18: 1. https://doi.org/10.1186/s12880-018-0245-9

44. Chang M, Marshall J (2012) Therapeutic hypothermia for acute air embolic stroke. West J Emerg Med 13:111-113

45. Iwuagwu OC, Felix EO (2010) Left ventricular and coronary air embolism complicating a routine CT-guided cavitating lung mass biopsy: a case report. Res J Med Sci 4:248-251

46. Dietrich A, Vargas A, Smith DE, Domenech A (2017) Intraventricular air embolism complicating computed tomography-guided pulmonary aspiration biopsy. Arch Bronconeumol 53:348-349

47. El Homsi M, Haydar A, Dughayli J, Al-Kutoubi A (2019) Transcatheter aspiration of systemic air embolism causing cardiac compromise during CT-guided lung biopsy, a potentially lifesaving maneuver. Cardiovasc Intervent Radiol 42:150-153

48. Fiore L, Frenk NE, Martins GLP, Viana PCC, de Menezes MR (2017) Systemic air embolism after percutaneous lung biopsy: a manageable complication. J Radiol Case Rep 11:6-14

49. Tomabechi M, Kato K, Sone M et al (2008) Cerebral air embolism treated with hyperbaric oxygen therapy following percutaneous transthoracic computed tomography-guided needle biopsy of the lung. Radiat Med 26:379-383

50. Franke M, Reinhardt HC, Von Bergwelt-Baildon M, Bangard C (2014) Massive air embolism after lung biopsy. Circulation 129: 1046-1047

51. Galvis JM, Nunley DR, Zheyi T, Dinglasan LAV (2017) Left ventricle and systemic air embolism after percutaneous lung biopsy. Respir Med Case Rep 22:206-208

52. Ghafoori M, Varedi P (2008) Systemic air embolism after percutaneous transthorasic needle biopsy of the lung. Emerg Radiol 15: 353-356

53. Hirasawa S, Hirasawa H, Taketomi-Takahashi A et al (2008) Air embolism detected during computed tomography fluoroscopically guided transthoracic needle biopsy. Cardiovasc Intervent Radiol 31:219-221

54. Hsi DH, Thompson TN, Fruchter A, Collins MS, Lieberg OU, Boepple H (2008) Simultaneous coronary and cerebral air embolism after CT-guided core needle biopsy of the lung. Tex Heart Inst J 35:472-474

55. Hung WH, Chang CC, Ho SY, Liao CY, Wang BY (2015) Systemic air embolism causing acute stroke and myocardial infarction after percutaneous transthoracic lung biopsy-a case report. J Cardiothorac Surg 10:121. https://doi.org/10.1186/s13019-0150329-3

56. Ialongo P, Ciarpaglini L, Tinti MD, Suadoni MN, Cardillo G (2017) Systemic air embolism as a complication of percutaneous computed tomography guided transthoracic lung biopsy. Ann R Coll Surg Engl 99:e174-e176

57. Ishikawa Y, Matsuguma H, Nakahara R, Ui A, Suzuki H, Yokoi K (2009) Arterial air embolism: a rare but life-threatening complication of percutaneous needle biopsy of the lung. Ann Thorac Surg 87:1622. https://doi.org/10.1016/j.athoracsur.2008.08.035

58. Karnatovskaia LV, Lee AS, Dababneh H, Lin A, Festic E (2012) Stress-induced cardiomyopathy complicating a stroke caused by an air embolism. J Bronchology Interv Pulmonol 19:224-227

59. Kau T, Rabitsch E, Celedin S, Habernig SM, Weber JR, Hausegger KA (2008) When coughing can cause stroke-a casebased update on cerebral air embolism complicating biopsy of the lung. Cardiovasc Intervent Radiol 31:848-853

60. Kawaji T, Shiomi H, Togashi Y et al (2012) Coronary air embolism and cardiogenic shock during computed tomography-guided needle biopsy of the lung. Circulation 126:e195-e197 
61. Kazimirko DN, Beam WB, Saleh K, Patel AM (2016) Beware of positive pressure: coronary artery air embolism following percutaneous lung biopsy. Radiol Case Rep 11:344-347

62. Cianci P, Posin JP, Shimshak RR, Singzon J (1987) Air embolism complicating percutaneous thin needle biopsy of lung. Chest 92: 749-751

63. Khalid F, Rehman S, AbdulRahman R, Gupta S (2018) Fatal air embolism following local anaesthetisation: does needle size matter? BMJ Case Rep 2018:bcr2017222254. https://doi.org/10. 1136/bcr-2017-222254

64. Khatri S (1997) Cerebral artery gas embolism (CAGE) following fine needle aspiration biopsy of the lung. Aust N Z J Med 27:338. https://doi.org/10.1111/j.1445-5994.1997.tb01989.x

65. Reguero Llorente E, Alonso García E (2019) Arterial air embolism after percutaneous lung biopsy. Radiologia 61:269-270

66. Kogut MJ, Linville RM, Bastawrous S, Padia SA, Maki JH, Bhargava P (2012) Systemic air embolization during percutaneous transthoracic needle biopsy: imaging findings, management strategies, and review of the literature. Clin Pulm Med 19:188 190

67. Kok HK, Leong S, Salati U, Torreggiani WC, Govender P (2013) Left atrial and systemic air embolism after lung biopsy: importance of treatment positioning. J Vasc Interv Radiol 24:1587-1588

68. Lang D, Reinelt V, Horner A et al (2018) Complications of CTguided transthoracic lung biopsy: a short report on current literature and a case of systemic air embolism. Wien Klin Wochenschr 130:288-292

69. Lattin G Jr, O'Brien W Sr, McCrary B, Kearney P, Gover D (2006) Massive systemic air embolism treated with hyperbaric oxygen therapy following CT-guided transthoracic needle biopsy of a pulmonary nodule. J Vasc Interv Radiol 17:1355-1358

70. Lederer W, Schlimp CJ, Glodny B, Wiedermann FJ (2011) Air embolism during CT-guided transthoracic needle biopsy. BMJ Case Rep 2011:bcr0420114113. https://doi.org/10.1136/bcr.04. 2011.4113

71. Lee WH (2016) Air embolization after computed tomographyguided percutaneous transthoracic needle biopsy. Soonchunhyang Med Sci 22:170-172

72. Mansour A, AbdelRaouf S, Qandeel M, Swaidan M (2005) Acute coronary artery air embolism following CT-guided lung biopsy. Cardiovasc Intervent Radiol 28:131-134

73. Matsuura H, Takaishi A, Oonishi N et al (2017) Air embolism and CT-guided lung biopsy. QJM 110:465-466

74. Matz S, Segal A, Nemesh L (1980) Diagnosis of air embolism to the brain by computerized axial tomography. Comput Tomogr 4: $107-110$

75. Deshmukh A, Kadavani N, Kakkar R, Desai S, Bhat GM (2019) Coronary artery air embolism complicating a CT-guided percutaneous lung biopsy. Indian J Radiol Imaging 29:81-84

76. Mokart D, Sarran A, Barthelemy A et al (2011) Systemic air embolism during lung biopsy. Br J Anaesth 107:277-278

77. Mokhlesi B, Ansaarie I, Bader M, Tareen M, Boatman J (2002) Coronary artery air embolism complicating a CT-guided transthoracic needle biopsy of the lung. Chest 121:993-996

78. Baker BK, Awwad EE (1988) Computed tomography of fatal cerebral air embolism following percutaneous aspiration biopsy of the lung. J Comput Assist Tomogr 12:1082-1083

79. Ohashi S, Endoh H, Honda T, Komura N, Satoh K (2001) Cerebral air embolism complicating percutaneous thin-needle biopsy of the lung: complete neurological recovery after hyperbaric oxygen therapy. J Anesth 15:233-236

80. Olgun DC, Samanci C, Ergin AS, Akman C (2015) Lifethreatening complication of percutaneous transthoracic fineneedle aspiration biopsy: systemic arterial air embolism. Eurasian J Med 47:72-74
81. Omenaas E, Moerkve O, Thomassen L et al (1989) Cerebral air embolism after transthoracic aspiration with a $0.6 \mathrm{~mm}$ (23 gauge) needle. Eur Respir J 2:908-910

82. Ornelas E, Fernandez-Vilches S, Gallardo X, Mesquida J (2018) Massive coronary air embolism after CT-guided lung needle biopsy. Intensive Care Med 44:1748-1749

83. Sood B, Rezaei S, Brodribb R (2012) Iatrogenic air embolism following CT-guided lung biopsy. Appl Radiol 41:43-46

84. Rahman ZU, Murtaza G, Pourmorteza M et al (2016) Cardiac arrest as a consequence of air embolism: a case report and literature review. Case Rep Med 2016:8236845. https://doi.org/10. $1155 / 2016 / 8236845$

85. Ramaswamy R, Narsinh KH, Tuan A, Kinney TB (2014) Systemic air embolism following percutaneous lung biopsy. Semin Intervent Radiol 31:375-377

86. Regge D, Gallo T, Galli J, Bertinetti A, Gallino C, Scappaticci E (1997) Systemic arterial air embolism and tension pneumothorax: two complications of transthoracic percutaneous thin-needle biopsy in the same patient. Eur Radiol 7:173-175

87. Rocha RD, Azevedo AA, Falsarella PM, Rahal A, Garcia RG (2015) Cerebral air embolism during CT-guided lung biopsy. Thorax 70:1099-1100

88. Rott G, Boecker F (2014) Influenceable and avoidable risk factors for systemic air embolism due to percutaneous CT-guided lung biopsy: patient positioning and coaxial biopsy technique - case report, systematic literature review, and a technical note. Radiol Res Pract 2014:349062. https://doi.org/10.1155/2014/349062

89. Sakatani T, Amano Y, Sato J, Nagase T (2018) Air embolism after CT-guided percutaneous lung biopsy. Jpn J Clin Oncol 48:699700

90. Ashizawa K, Watanabe H, Morooka H, Hayashi K (2004) Hyperbaric oxygen therapy for air embolism complicating CTguided needle biopsy of the lung. AJR Am J Roentgenol 182: 1606-1607

91. Shin KM, Lim JK, Kim CH (2014) Delayed presentation of cerebellar and spinal cord infarction as a complication of computed tomography-guided transthoracic lung biopsy: a case report. J Med Case Reports 8:272. https://doi.org/10.1186/1752-1947-8272

92. Shroff GR, Sarraf M, Sprenkle MD, Karim RM (2011) Air embolism involving the coronary and pulmonary circulation: an unusual cause of sudden cardiac death. Circulation 124:2949-2950

93. Singh A, Ramanakumar A, Hannan J (2011) Simultaneous left ventricular and cerebral artery air embolism after computed tomographic-guided transthoracic needle biopsy of the lung. Tex Heart Inst J 38:424-426

94. Smit DR, Kleijn SA, de Voogt WG (2013) Coronary and cerebral air embolism: a rare complication of computed tomographyguided transthoracic lung biopsy. Neth Heart J 21:464-466

95. Pereira P (1993) A fatal case of cerebral artery gas embolism following fine needle biopsy of the lung. Med J Aust 159:755-757

96. Suzuki K, Ueda M, Muraga K et al (2013) An unusual cerebral air embolism developing within the posterior circulation territory after a needle lung biopsy. Intern Med 52:115-117

97. Yoshida R, Yoshizako T, Nakamura M et al (2018) Nonfatal air embolism complicating percutaneous CT-guided lung biopsy and VATS marking: four cases from a single institution. Clin Imaging 48:127-130

98. Yamamoto A, Suzuki K, Iwashita Y et al (2016) Controlled normothermia for a cerebral air embolism complicating computed tomography-guided transthoracic needle biopsy of the lung. Acute Med Surg 3:411-414

99. Thomas R, Thangakunam B, Cherian RA, Gupta R, Christopher DJ (2011) Cerebral air embolism complicating CT-guided transthoracic needle biopsy of the lung. Clin Respir J 5:e1-e3 
100. Shi L, Zhang R, Wang Z, Zhou P (2013) Delayed cerebral air embolism complicating percutaneous needle biopsy of the lung. Am J Med Sci 345:501-503

101. Tsetsou S, Eeckhout E, Qanadli SD, Lachenal Y, Vingerhoets F, Michel P (2013) Non-accidental arterial cerebral air embolism: a 10-year stroke center experience. Cerebrovasc Dis 35:392-395

102. Um SJ, Lee SK, Doo KY et al (2009) Four cases of a cerebral air embolism complicating a percutaneous transthoracic needle biopsy. Korean J Radiol 10:81-84

103. Wu YF, Huang TW, Kao CC, Lee SC (2012) Air embolism complicating computed tomography-guided core needle biopsy of the lung. Interact Cardiovasc Thorac Surg 14:771-772

104. Viqas Z, Yar A, Yaseen M, Khalid M (2018) Cardiac arrest due to air embolism: complicating image-guided lung biopsy. Cureus 10: e3295. https://doi.org/10.7759/cureus.3295

105. Westcott JL (1973) Air embolism complicating percutaneous needle biopsy of the lung. Chest 63:108-110

106. Wong RS, Ketai L, Temes RT, Follis FM, Ashby R (1995) Air embolus complicating transthoracic percutaneous needle biopsy. Ann Thorac Surg 59:1010-1011

107. Tavare AN, Patel A, Saini A, Creer DD, Hare SS (2018) Systemic air embolism as a complication of percutaneous lung biopsy. Br J Hosp Med (Lond) 79:106-107

108. Marchak K, Hong MJ, Schramm KM (2019) Systemic air embolism following CT-guided percutaneous core needle biopsy of the lung: case report and review of the literature. Semin Intervent Radiol 36:68-71

109. Hellinger L, Keppler A, Schoeppenthau H, Perras J, Bender R (2019) Hyperbaric oxygen therapy for iatrogenic arterial gas embolism after CT-guided lung biopsy : a case report. Anaesthesist 68:456-460

110. Warren S, Somers A, Chambers B, Gardner K (2019) A case study: percutaneous lung biopsy and symptomatic arterial air embolus. J Radiol Nurs 38:174-176

111. Oliva RA, de Miguel DJ, Puente ML, de la Torre FJ (2019) Arterial gas embolism: a rare complication of core needle biopsy in the diagnosis of solitary pulmonary nodule. Arch Bronconeumol 55:492-493

112. Abid H, Kumar A, Siddiqui N, Kramer B (2019) Systemic air embolism following computed tomography-guided lung biopsy. Cureus 11:e5408. https://doi.org/10.7759/cureus.5408

113. Muth CM, Shank ES (2000) Gas embolism. N Engl J Med 342: 476-482

114. Coulter TD, Wiedemann HP (2000) Gas embolism. N Engl J Med 342:2000. https://doi.org/10.1056/NEJM200006293422617

115. Balsara ZN, Burks DD (2007) Hyperbaric oxygen therapy for arterial air embolism. AJR Am J Roentgenol 188:W98-W98

Publisher's note Springer Nature remains neutral with regard to jurisdictional claims in published maps and institutional affiliations. 